\title{
Intensification of Paraxylene Production using a Simulated Moving Bed Reactor
}

\author{
G. Bergeot ${ }^{1}$, D. Leinekugel-Le-Cocq ${ }^{1}$, L. Wolff' ${ }^{1}$, L. Muhr ${ }^{2}$ and M. Bailly ${ }^{2}$ \\ 1 IFP Energies nouvelles-Lyon, Rond-point de l'échangeur de Solaize, BP 3, 69360 Solaize - France \\ 2 LSGC - ENSIC-CNRS, 1 rue de Granville, BP 20451, 54001 Nancy - France \\ e-mail: ghislain.bergeot@ifpenergiesnouvelles.fr - damien.leinekugel@ifpenergiesnouvelles.fr - Laurence.Muhr@ensic.inpl-nancy.fr \\ bailly@ensic.inpl-nancy.fr
}

Résumé - Intensification de la production de paraxylène à l'aide du lit mobile simulé réactif Les réacteurs multifonctionnels, qui associent une étape de séparation et une étape de réaction dans une seule et même unité, constituent un axe de développement important dans le domaine de l'écoconception des procédés afin de réduire les coûts énergétiques et environnementaux. Ils permettent de réduire, voire d'éliminer, les flux de recyclage et la taille des unités afin d'obtenir des procédés moins coûteux et plus sûrs.

Cet article présente l'étude d'un réacteur multifonctionnel couplant une réaction d'isomérisation et une séparation par adsorption : le Lit Mobile Simulé Réactif (LMSR). Ce procédé est appliqué à la séparation réactive des xylènes. Le procédé actuel permet de produire du paraxylène (PX) pur (à plus de 99,7\%) à partir d'un mélange d'isomères grâce à une étape de séparation par Lit Mobile Simulé (LMS) et une étape d'isomérisation en phase gaz. La majeure partie de l'alimentation du LMS provient du recyclage des isomères du paraxylène qui sont transformés dans le réacteur. La séparation réactive, en intégrant l'isomérisation dans le LMS, devrait permettre de réduire ce flux de recyclage et les utilités associées.

La séparation des xylènes s'effectuant en phase liquide, la première étape de cette étude a donc été de vérifier la faisabilité de la réaction en phase liquide. Ces tests ont permis de valider l'utilisation de la zéolithe HZSM-5 comme catalyseur de la réaction et du toluène comme désorbant pour la séparation (à la place du paradiéthylbenzène, plus classiquement utilisé, mais qui s'isomérise au contact de ce catalyseur). Les données expérimentales ont permis d'estimer des paramètres cinétiques pour un modèle d'isomérisation en phase liquide des xylènes. Ce modèle a été ajouté à un modèle de séparation par Lit Mobile Vrai (LMV) pour obtenir un simulateur de Lit Mobile Vrai Réactif (LMVR). Grâce à ce simulateur de LMVR, les conditions de fonctionnement du procédé LMSR ont pu être déterminées. Ces conditions de fonctionnement montrent qu'il est possible de réduire le flux de recyclage de plus de $40 \%$ tout en conservant la même productivité. Une étude comparative des deux schémas de production de PX dans leur globalité permet d'espérer une réduction des coûts d'investissement et des coûts opératoires grâce au procédé LMSR.

\footnotetext{
Abstract - Intensification of Paraxylene Production using a Simulated Moving Bed Reactor Multifunctional reactors, which combine a reaction step and a separation step in one single unit, constitute an important advance in design of sustainable processes to save energy and reduce environmental impact. They allow reductions of recycle flows and size units in order to have more safety and less expansive processes. This paper deals with separation by adsorption and reaction coupled in a Simulated Moving Bed reactor (SMBR) for paraxylene (PX) production. In the current industrial process, the major part of the separation step comes from a recycle flow where the $C_{8}$ aromatics are isomerized. The SMBR, by decreasing this recycle stream, may reduce the energy needed to treat and
} 
convert the raffinate into a rich PX stream. As separation takes place in the liquid phase, the first part of this paper establishes the feasibility of liquid phase isomerization of xylene. Tests in a fixed bed reactor validate the use of a HZSM-5 zeolite catalyst. Paradiethylbenzene (paraDEB), the classical desorbent used in xylene separation, isomerizes into orthodiethylbenzene and metadiethylbenzene so it is replaced by toluene. Experimental data permit one to estimate the parameters used in a simple analytical model implemented in a classical True Moving Bed model. This TMBR model permits to find the various operating regimes of such a SMBR. The conditions found allow a $40 \%$ reduction of the recycle flow without any productivity loss. With this lower recycle flow, a reduction of investment and operating costs is expected on the global PX production process thanks to the SMBR process.

\section{NOTATION}

A Cross-sectional area of an adsorption bed $\left(\mathrm{m}^{2}\right)$

$B_{i} \quad$ Langmuir constant of component $i\left(\mathrm{~m}^{3} / \mathrm{kg}\right)$

$C_{i} \quad$ Concentration of component $i\left(\mathrm{~kg} / \mathrm{m}^{3}\right)$

$C_{\text {TOTAL }}$ Total concentration in the reactor $\left(\mathrm{kg} / \mathrm{m}^{3}\right)$

$E_{a i} \quad$ Activation energy of the reaction $i(\mathrm{~J} / \mathrm{mol})$

$k_{i} \quad$ Kinetic constant of reaction $i\left(\mathrm{~s}^{-1}\right)$

$k_{i}^{\prime} \quad$ Apparent kinetic constant of reaction $i\left(\mathrm{~m}^{3} / \mathrm{kg} / \mathrm{s}\right)$

$k_{0 i} \quad$ Kinetic parameter of the kinetic constant of reaction $i\left(\mathrm{~m}^{3} / \mathrm{kg} / \mathrm{s}\right)$

$k_{\text {LDFmacro }}$ LDF coefficient for the macropore phase

$k_{\text {LDFmicro }}$ LDF coefficient for the micropore phase

$L_{C} \quad$ Length of an adsorption bed (m)

$N_{\text {bed }} \quad$ Total number of adsorption bed

$P \quad$ Total pressure

$q_{\text {sat }} \quad$ Total saturation capacity of adsorbed species $(\mathrm{kg} / \mathrm{kg})$

$Q_{S M B} \quad$ Volume flow rate in $\mathrm{SMB}\left(\mathrm{m}^{3} / \mathrm{s}\right)$

$Q_{T M B} \quad$ Volume flow rate in the equivalent TMB $\left(\mathrm{m}^{3} / \mathrm{s}\right)$

$Q_{s} \quad$ Solid volume flow rate $\left(\mathrm{m}^{3} / \mathrm{s}\right)$

$Q^{j} \quad$ Volume flow rate of $j$ flow rate $\left(\mathrm{m}^{3} / \mathrm{s}\right)$

$R \quad$ Ideal gas constant $(\mathrm{J} / \mathrm{K} / \mathrm{mol})$

$\Delta t^{s W} \quad$ Switching time (s)

$T \quad$ Temperature

$u_{s} \quad$ Interstitial solid velocity $(\mathrm{m} / \mathrm{s})$

$v \quad$ Interstitial velocity in the isomerization reactor $(\mathrm{m} / \mathrm{s})$

$V_{\text {bed }} \quad$ Total volume of one adsorption bed $\left(\mathrm{m}^{3}\right)$

$v_{S M B} \quad$ Interstitial velocity in SMB process $(\mathrm{m} / \mathrm{s})$

$v_{T M B} \quad$ Interstitial velocity in TMB process $(\mathrm{m} / \mathrm{s})$

$x_{i}^{j} \quad$ Molar fraction of $i$ component in $j$ flow rate

$z \quad$ Coordinate of the isomerization reactor $(\mathrm{m})$

$\varepsilon \quad$ Void fraction of the adsorption bed

$\varepsilon_{\text {reactor }}$ Void fraction of the isomerization reactor

$\rho_{\text {catalyst }}$ Catalyst density $\left(\mathrm{kg} / \mathrm{m}^{3}\right)$

\section{Subscript and Superscript}

EB Ethylbenzene

MX Metaxylene

$\begin{array}{ll}\text { OX } & \text { Orthoxylene } \\ \text { PX } & \text { Paraxylene } \\ \text { X } & \text { Extract } \\ \text { F } & \text { Feed }\end{array}$

\section{INTRODUCTION}

In the current energetic context, many studies are done in the field of sustainable process design. Sustainable process design consists of modifying processes to reduce investment costs, operating costs and environmental impact. Multifunctional reactors combine a reaction and a separation step in one single unit. They constitute an important advance in sustainable process design. Coupling reaction and separation permits one to reduce the operating costs for the downstream purification step by shifting the chemical equilibrium. Although the most known reactive separation process is reactive distillation, reaction and adsorption have been combined in numerous studies over the last ten years. First studied in 1976 by Takeuchi and Uraguchi for CO oxidation (Takeuchi and Uraguchi, 1976), the Simulated Moving Bed Reactor (SMBR) has been investigated for other systems in relation to the growing success of SMB industrialization. This paper deals with the feasibility of the SMBR applied to PX production, one of the most important industrial applications of the SMB. PX is mostly used to produce terephthalic acid, which is the raw material of polyethylene terephtalate (PET).

Figure 1 represents a classical PX production plant: a SMB unit separates paraxylene (PX) from orthoxylene (OX), metaxylene (MX) and ethylbenzene (EB). The other isomers are recycled in an isomerization reactor. This recycle loop constitutes the major part of the SMB feed (Fig. 1). The plant also includes three distillation columns and an isomerization reactor. Including a $\mathrm{C}_{8}$ aromatic isomerization step in the SMB may reduce the recycle loop. As a consequence, lower energetic and economic costs could be obtained with smaller distillation columns and reactor.

After a presentation of the SMB and SMBR principles, the feasibility of liquid phase isomerization of xylene is studied. The second part of this paper deals with SMBR results, obtained by simulation, and the reduction of the recycle loop that might be obtained with the SMBR process. 


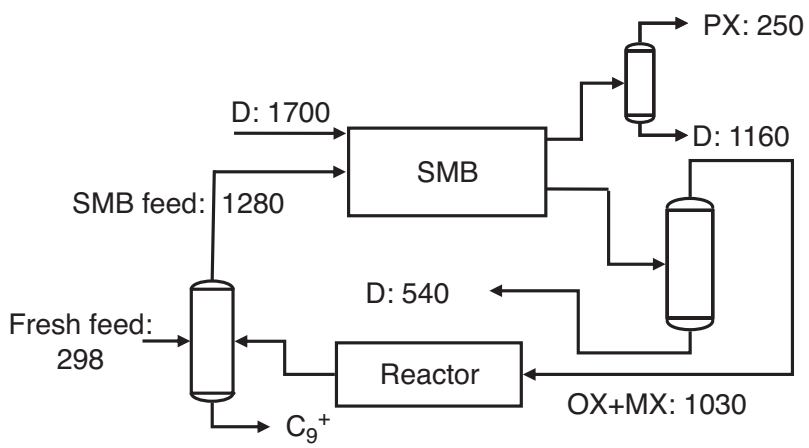

Figure 1

Classical PX production plant for $250 \mathrm{kT}$ per year of PX.

\section{SMB AND SMBR PRINCIPLES}

The SMB process constitutes a major advance in liquid phase chromatography. It is a continuous chromatographic process based on a counter-current contact between a solid phase and fluid phase (liquid or gas). With the addition of reaction to the separation process, SMBR permits one to shift the chemical equilibrium, and the operating cost for downstream purification can be reduced.

\subsection{SMB Principle}

The SMB is derived from the True Moving Bed (TMB), where the solid and the liquid move along the adsorber. Let us consider a downflow solid phase stream in contact with an upflow liquid phase stream. The feed mixture is introduced into the column and the most adsorbed component is carried by the solid to the bottom of the column, whereas the less retained component is carried upward with the mobile phase (Fig. 2a). Most TMB systems have four zones delimited by the inlets and outlets of the process (Fig. 2a). Each zone has a specific function. Zone 1 desorbs the most retained component (A), zone 2 purifies this component, zone 3 purifies the less retained component (B) and the last zone purifies the desorbent for recycling.

Having a solid flow is hardly feasible in large-scale industrial unit, so SMB is preferred. A SMB is made of several interconnected fixed beds (12 in Fig. 2b). The counter-current is simulated by a periodic switching of inlets and outlets in the direction of the fluid flow. The time span between the switching of port location is called switching time. After several cycles, the process reaches a cyclic steady state.

In the last fifteen years, reaction has been introduced into SMB processes to shift the chemical equilibrium of unfavorable reaction for systems where the product separation can be obtained by adsorption.

\subsection{SMBR Principle}

The counter-current chromatographic processes have been applied to reactive systems since the mid-seventies (Takeuchi and Uraguchi, 1976). Based on the first chromatographic reactors, which appeared in the early sixties (Sardin et al., 1993), most of the Simulated Moving Bed Reactors are applied to an A (+ B) $\leftrightarrow \mathrm{C}+\mathrm{D}$ type of reaction. To achieve the reaction, a catalyst can be mixed with the adsorbent, with the desorbent (homogenous catalysis (Ganetsos et al., 1993)), or an adsorbent with catalyst function can be used (Takeuchi
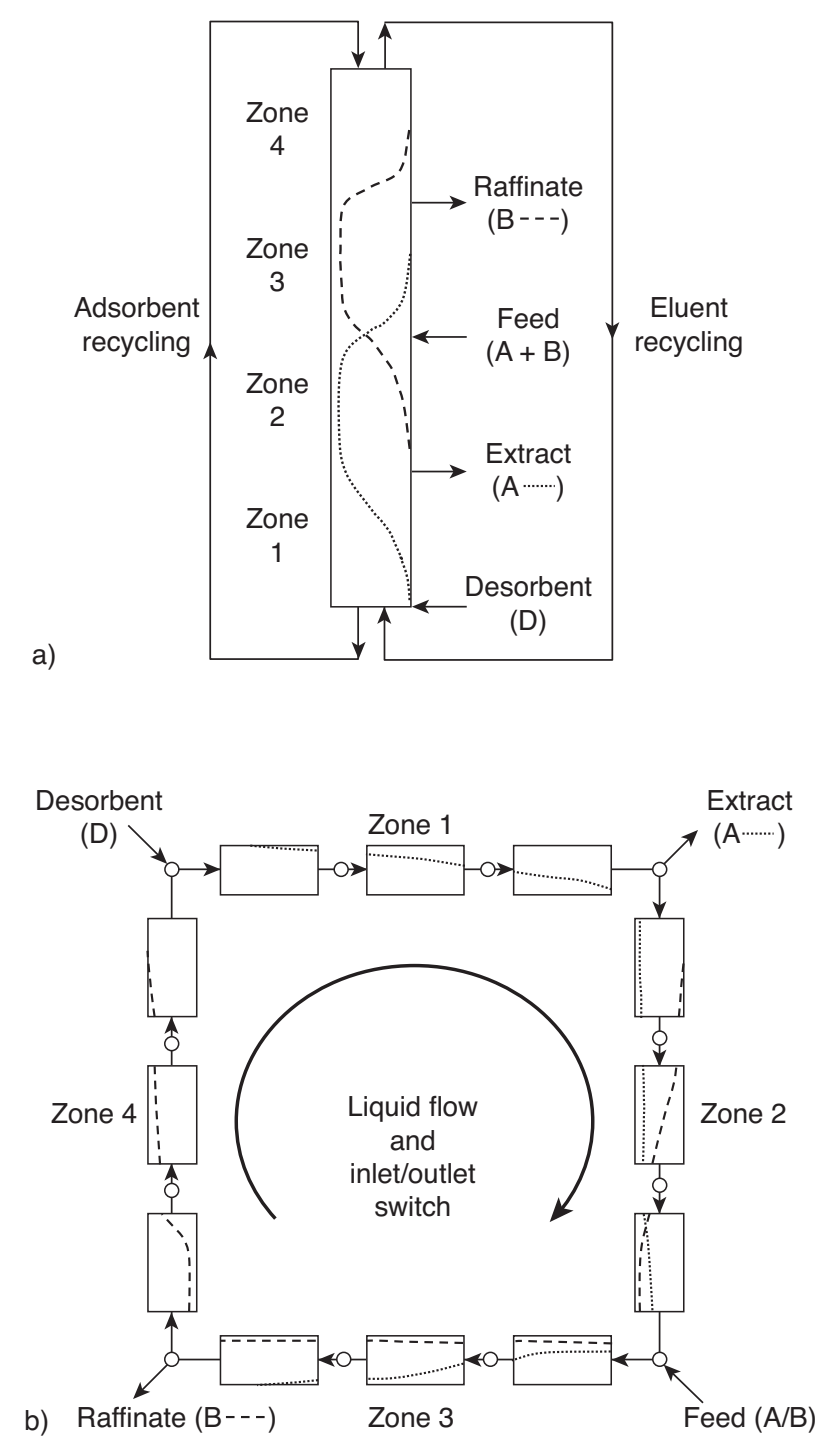

Figure 2

TMB a) and SMB b) applied to separating a mixture of two components, $\mathrm{A} / \mathrm{B}$. 
a)

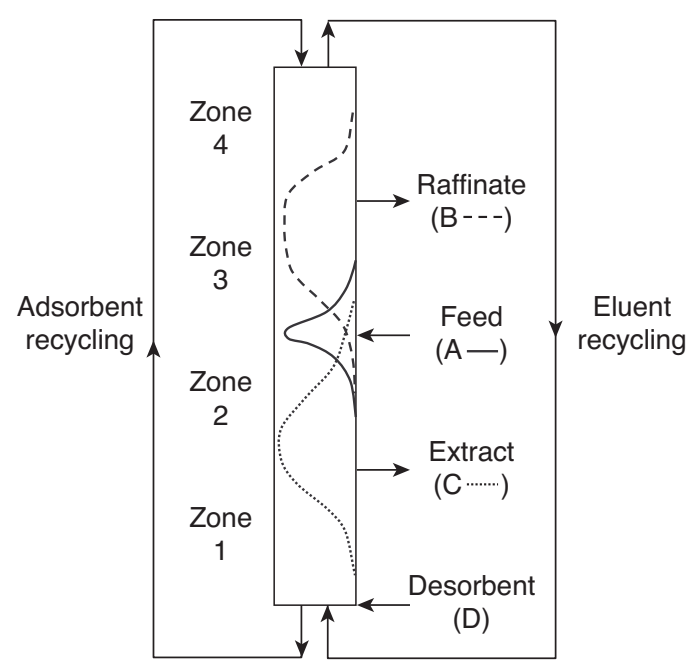

Figure 3

TMBR a) and SMBR b) for the reaction $\mathrm{A} \leftrightarrow \mathrm{B}+\mathrm{C}$.

and Uraguchi, 1977; Dulot, 2000; Lode et al., 2001). For those cases, the SMBR process is the same as a non-reactive $\mathrm{SMB}$. The feed is composed of reactant A and, while the reaction occurs, products are separated by adsorption. The less adsorbed product is carried to the extract by the fluid phase and the most retained product moves to the raffinate with the solid phase (Fig. 3b).

Many publications have established the efficiency of a SMBR for $\mathrm{A} \leftrightarrow \mathrm{B}+\mathrm{C}$ (sucrose inversion (Ganetsos et al., 1993; Kurup et al., 2005), esterification (Lode et al., 2001), toluene disproportionation (Dulot, 2000), hydrolysis methyl acetate (Yu et al., 2005)) but only few studies on the A $\leftrightarrow$ B reactive system have been published.

When the product is the less retained component, a twozone SMBR is feasible for an $\mathrm{A} \leftrightarrow \mathrm{B}$ type of reaction. The most strongly adsorbed component is created and directly adsorbed near the raffinate point so the less adsorbed component can be recovered. Practically, high purity cannot be reached (the maximum purity obtained is around 96\%) (Fish et al., 1986).

For PX production, PX is the most retained component and extract purity specification is very high (more than 99.7\%). If the catalyst and adsorbent are mixed, the reaction will occur in all the adsorber and high purity cannot be obtained. The catalyst and adsorbent have to be separated for PX production.

\subsection{The SMBR for PX Production}

If a reagent $\mathrm{A}$ is in contact with the catalyst in the all of the process, it reacts to form component B. So neither pure A nor pure $\mathrm{B}$ can be produced.

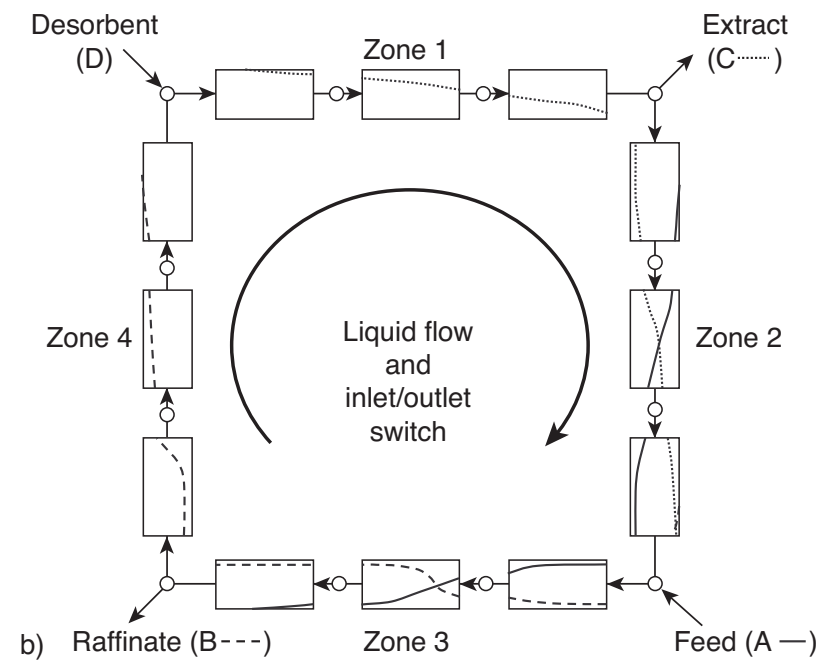

A solution consists of inserting reactors between the adsorption columns far from the extract point. Hashimoto $e t$ $a l$. achieved the isomerization of glucose into fructose with reactors in the third zone (Hashimoto et al., 1983). Minceva et al. used a similar scheme to simulate a SMBR with four zones for PX production (Minceva et al., 2008). Zone 1 regenerates the adsorbent by desorbing PX. Zone 4 regenerates the desorbent by adsorbing MX, OX and EB. Zone 2 separates PX from other isomers. Zone 3, where reactors are inserted, alternately separates and produces PX (Fig. 4). As xylene separation takes place in the liquid phase, a liquid phase isomerization of xylene was studied to be able to connect catalyst beds to adsorption beds. A part of this study has already been presented elsewhere (Bergeot $e t$ al., 2009).

\section{LIQUID PHASE ISOMERIZATION OF XYLENE}

In the classical industrial plant, xylene isomerization takes place in the gas phase under hydrogen pressure. Those conditions are necessary in order to convert ethylbenzene (EB), naturally present in SMB feeds. In the SMBR case, isomerization has to be carried out in the liquid phase without hydrogen. In those conditions, EB cannot be converted. EB may be separated from the feed before the SMBR (using, for example, a membrane).

Few data are available in the literature on liquid phase isomerization of xylene. Tests have been carried out to validate the catalyst and the operating conditions (temperature, pressure, weight hourly space velocity (whsv), desorbent used, etc.). 


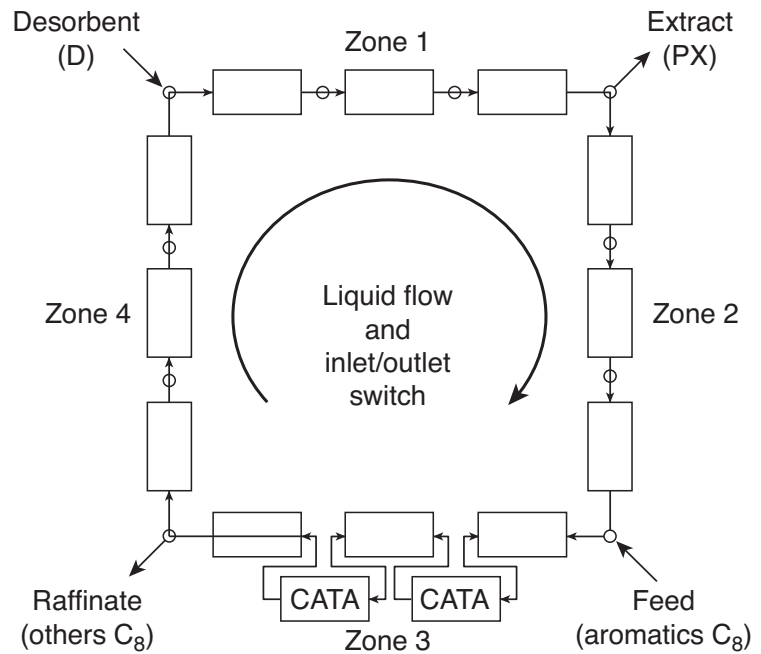

Figure 4

SMBR for PX production with a 3-3-3+2-3 repartition of adsorbent beds and reactors.

\subsection{Experiment}

Isomerization tests were carried out with an extruded HZSM-5 zeolite as catalyst (classically used for xylene isomerization). The reactor has a $22-\mathrm{mm}$ internal diameter for a $1342-\mathrm{mm}$ length. It was used on upflow conditions.

In all tests, a length of $245 \mathrm{~mm}$ of the reactor was packed either with $60 \mathrm{~g}$ of catalyst or with $30 \mathrm{~g}$ of catalyst diluted with glass beads. In both cases, the void fraction in the catalyst bed is around 0.32 . The remaining part of the reactor was packed with glass beads. The following operating conditions were tested:

- temperature $(T): 200^{\circ} \mathrm{C}, 250^{\circ} \mathrm{C}, 300^{\circ} \mathrm{C}$;

- whsv from 5 to $30 \mathrm{~h}^{-1}$; the weight hourly space velocity is the ratio of OX mass flow rate to the mass of the catalyst $(\mathrm{g} / \mathrm{h}$ of $\mathrm{OX} / \mathrm{g}$ of catalyst);

- pressure ( $P$ ): 30 bar (to stay in liquid phase).

The feed was composed either of pure orthoxylene (OX), of a mix of OX and para-diethylbezene or of a mix of OX

TABLE 1

OX, MX and PX mole fractions at the thermodynamic equilibrium at $250^{\circ} \mathrm{C}$ and $300^{\circ} \mathrm{C}$ (Chirico and Steele, 1997)

\begin{tabular}{l|c|c}
\hline \multirow{3}{*}{$250^{\circ} \mathrm{C}$} & OX & 0.2298 \\
& MX & 0.5318 \\
& PX & 0.2385 \\
\hline \multirow{3}{*}{$300^{\circ} \mathrm{C}$} & OX & 0.2311 \\
& MX & 0.5284 \\
& PX & 0.2405 \\
\hline
\end{tabular}

and toluene. Those two mixtures were studied to check desorbent behavior in reactive conditions.

For each test, the performance was evaluated with the equilibrium approach (ratio of the PX produced to the PX at thermodynamic equilibrium, \%EA) in steady state. The chosen equilibrium thermodynamic data found in the literature (Chirico and Steele, 1997) are presented in Table 1 at $250^{\circ} \mathrm{C}$ and $300^{\circ} \mathrm{C}$.

\subsection{Results}

In a SMBR, $\mathrm{C}_{8}$ aromatics and desorbent concentrations vary along the adsorber. In the third zone, where isomerization reactors will be inserted, a significant desorbent quantity is present. Firstly, the compatibility between the desorbents and the catalyst was tested. Then, a pure OX feed was used to test several operating conditions ( $T$, whsv). Finally, results with pure OX feed were compared with results with a $50 \%$ $\mathrm{OX} / 50 \%$ desorbent feed.

\subsubsection{Desorbent Choice}

The first desorbent tested was paradiethylbenzene (PDEB), which is the most used desorbent in industrial units. Those tests revealed that PDEB isomerizes into ortho-diethylbenzene (ODEB) and meta-diethylbenzene (MDEB). As PDEB should probably be adsorbed preferentially to ODEB and MDEB, the desorbent adsorptivity may vary along the adsorber using PDEB as a desorbent in the SMBR process. It could raise a problem in tuning the flow rates of the SMBR. Thus, toluene (TOL, still used in several industrial SMB) was tested as a potential desorbent for the SMBR process. Since toluene showed no problem of secondary reactions, it was selected as a desorbent for the SMBR process.

\subsubsection{Temperature Effect}

Figure 5 presents the evolution of the \%EA for different temperatures and for a pure OX feed at a fixed whsv of $5 \mathrm{~h}^{-1}$. At $200^{\circ} \mathrm{C}$, the conversion level is low $(\% \mathrm{EA}=10 \%)$. An interesting conversion was reached at $250^{\circ} \mathrm{C}(70 \%)$. At $300^{\circ} \mathrm{C}$, the conversion was very close to the equilibrium $(96 \%)$. Reaction has to be carried out preferentially at $300^{\circ} \mathrm{C}$. This temperature was used to evaluate the whsv influence.

\subsubsection{Effect of Residence Time}

The influence of the whsv on \%EA was studied by conducting three runs at a fixed temperature $\left(300^{\circ} \mathrm{C}\right)$. The results are presented in Figure 6. The \%EA decreased when whsv increased. However, the \%EA is high (\%EA > 88\%), even with short residence time.

\subsubsection{Secondary Reactions}

To study the potential secondary reactions, the amount of impurities was analyzed for every test (Fig. 7). When the 


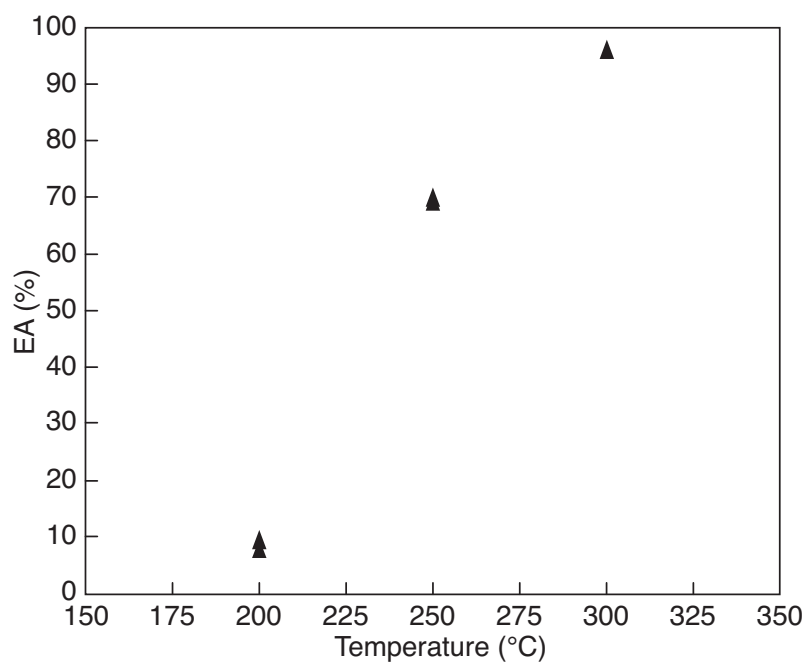

Figure 5

Evolution of \%EA for various temperatures - whsv $=5 \mathrm{~h}^{-1}$, pure $\mathrm{OX}$ feed, $P=30$ bar.

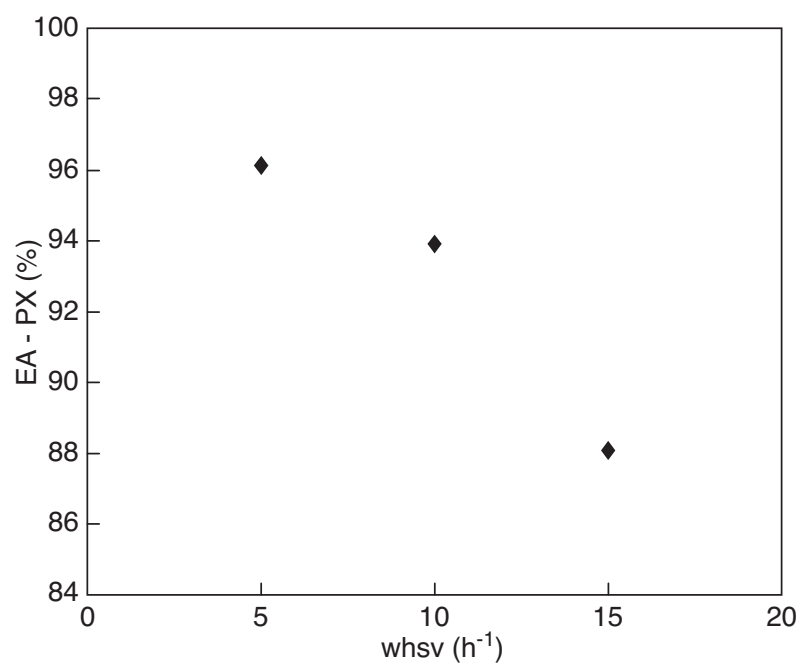

Figure 6

Evolution of $\%$ EA for various whsv $-T=300^{\circ} \mathrm{C}$, pure OX feed, $P=30$ bar.

EA\% increases, i.e. when temperature and/or whsv are higher, impurities increase.

The main impurities are trimethyl-benzene (TMBe) and toluene, together with small quantities of benzene and $\mathrm{C}_{10+}$ aromatics. TMBe and TOL probably result in xylene disproportionation. The other impurities come from reactions between impurities (TOL disproportionation, TMBe disproportionation, etc.). All those impurities are already present in SMB feeds so they may not have more impact on the reactive separation process than on the separation process.

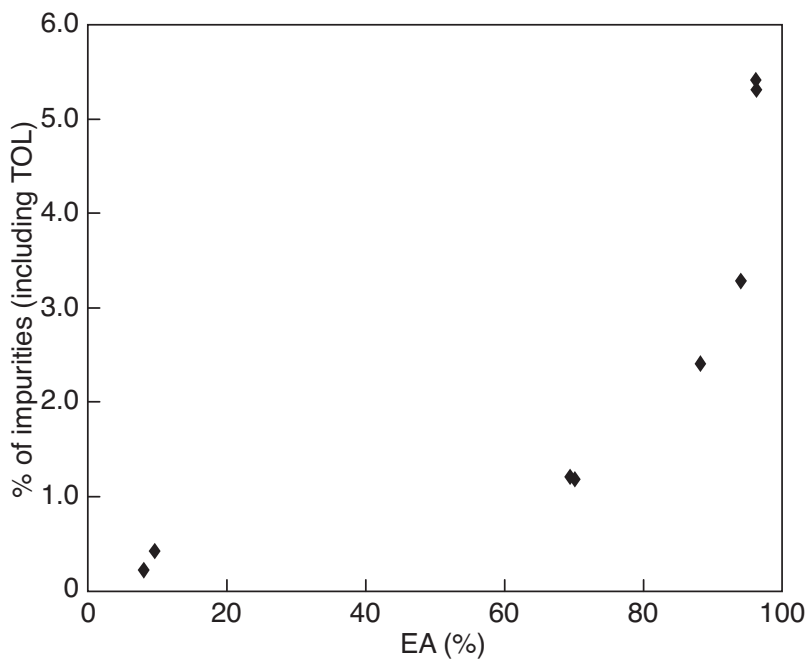

Figure 7

Evolution of the impurity percentage for various EA\% (pure OX feed).

The last point to confirm was the influence of the desorbent on equilibrium approach and on impurities.

\subsubsection{Influence of the Desorbent}

To test the desorbent's influence on reactions, a $50 \%$ OX/50\% TOL feed was used. The obtained conversions are compared with those obtained with pure OX feed (Fig. 8).

At $300^{\circ} \mathrm{C}$, results are similar with or without TOL. Dilution with TOL has no effect on the catalyst performances. \%EA is acceptable, even at high whsv $\left(77 \%\right.$ at $\left.30 \mathrm{~h}^{-1}\right)$.

The amount of impurities with a diluted feed was also investigated. As TOL is the desorbent, it is no longer considered as an impurity. It has been removed from the impurity amount of the previous results. At $300^{\circ} \mathrm{C}$, global impurities are equal with or without desorbent (Fig. 9). However, a higher benzene concentration and a lower TMBe concentration are observed. Lower TMBe concentration can be explained by chemical equilibrium shifting of the xylene disproportionation. As this reaction produces TMBe and TOL, the significant amount of TOL present in the feed shifts the chemical equilibrium in favor of xylene. Benzene is produced by TOL disproportionation. TOL in the feed shifts the chemical equilibrium of TOL disproportionation and produces more benzene than pure OX feed. Despite those differences, the global amount of impurities is equal and does not compromise the operation of the SMBR.

These isomerization tests validate HZSM- 5 as a possible catalyst for PX production by SMBR with TOL as a desorbent in a range of temperatures from $250^{\circ} \mathrm{C}$ to $300^{\circ} \mathrm{C}$. They also enable the estimation of parameters for a simplified analytical model for liquid phase xylene isomerization. 


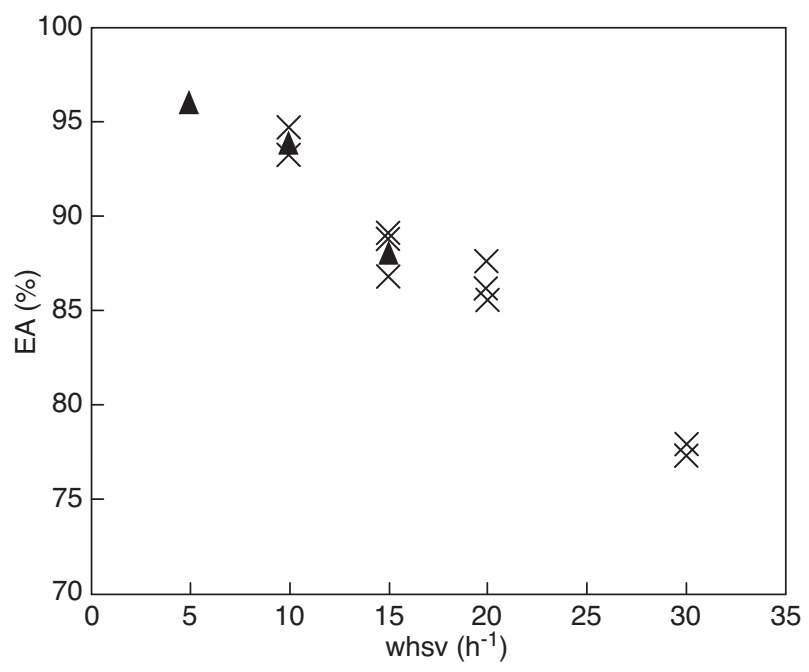

Figure 8

Comparison of the $\% \mathrm{EA}$ for different feeds at $300^{\circ} \mathrm{C} v s$ whsv $(\boldsymbol{\Delta}$ pure OX feed, $\times$ diluted feed).

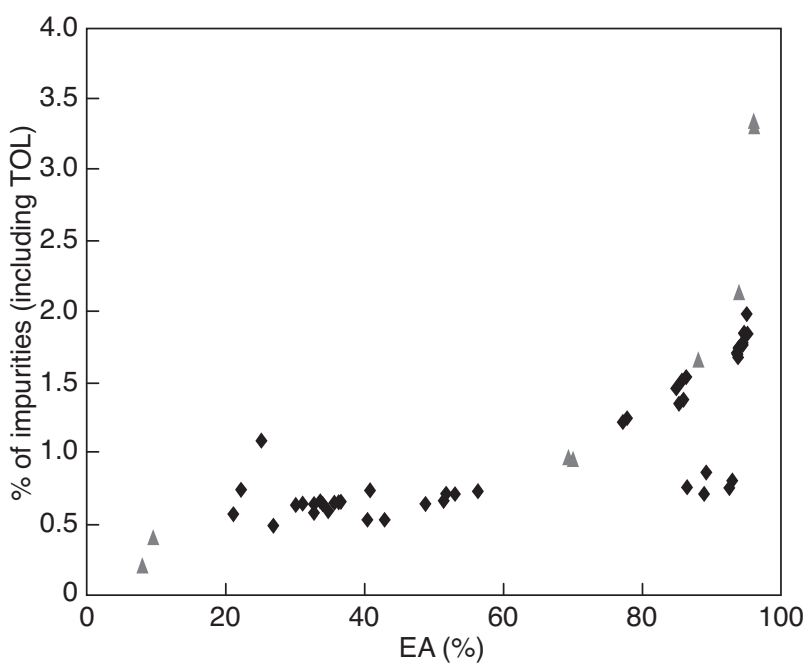

Figure 9

Influence of the desorbent dilution of the feed on the $\%$ of impurities ( $\Delta$ pure OX feed, $\bullet$ diluted feed).

\subsection{Modeling Isomerization}

SMB simulations are complex and need dynamics models. These models require significant computation time. So, in order to limit computation time, a simple analytical model was developed to describe isomerization steps.

The chosen reaction scheme for the analytical model is shown in Figure 10. The direct OX-PX reaction does certainly does not occur but readily represents the secondary reactions that produce PX from OX without passing to MX as a reactional intermediate.

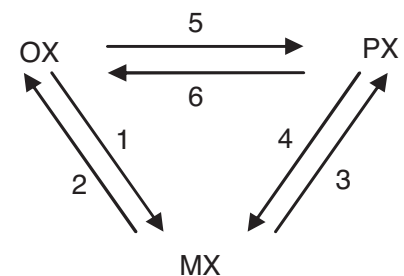

Figure 10

Reaction scheme used to represent xylene isomerization.

Classical mass balances for each component considering a plug flow reactor at steady state give a differential equation system $(E q .1)$. The $k_{i}$ are apparent kinetic constants of the reaction $i$ (Fig. 10). They include the fixed bed catalyst characteristics (Eq.2).

$$
\left\{\begin{array}{l}
v \frac{d C_{O X}}{d z}=\left(k_{6}-k_{2}\right) C_{P X}-\left(k_{2}+k_{5}+k_{1}\right) C_{O X}+k_{2} C_{T O T A L E} \\
v \frac{d C_{P X}}{d z}=\left(k_{5}-k_{3}\right) C_{O X}-\left(k_{3}+k_{4}+k_{6}\right) C_{P X}+k_{3} C_{T O T A L E} \\
C_{O X}+C_{M X}+C_{P X}=C_{T O T A L E} \\
k_{i}=\frac{1-\varepsilon_{\text {reactor }}}{\varepsilon_{\text {reactor }}} \rho_{\text {catalyst }} k_{0 i}^{\prime} \exp \left(\frac{-E_{a i}}{R T_{\text {reaction }}}\right)
\end{array}\right.
$$

The general solution of this differential equation system can be found analytically. The kinetics constants used were estimated using experimental data (Tab. 2).

TABLE 2

Kinetics, reactor and catalyst parameters used in the model of liquid phase isomerization of xylene

\begin{tabular}{l|c|l|l|l|l}
\hline$k_{01}^{\prime}$ & $1.1345 \times 10^{4}$ & $\mathrm{~m}^{3} \cdot \mathrm{kg}^{-1} \cdot \mathrm{s}^{-1}$ & $E_{a 1}$ & $1.0612 \times 10^{5}$ & $\mathrm{~J} \cdot \mathrm{mol}^{-1}$ \\
\hline$k_{02}^{\prime}$ & $4.0218 \times 10^{3}$ & $\mathrm{~m}^{3} \cdot \mathrm{kg}^{-1} \cdot \mathrm{s}^{-1}$ & $E_{a 2}$ & $1.0612 \times 10^{5}$ & $\mathrm{~J} \cdot \mathrm{mol}^{-1}$ \\
\hline$k_{03}^{\prime}$ & $6.7513 \times 10^{-7}$ & $\mathrm{~m}^{3} \cdot \mathrm{kg}^{-1} \cdot \mathrm{s}^{-1}$ & $E_{a 3}$ & $-2.0227 \times 10^{4}$ & $\mathrm{~J} \cdot \mathrm{mol}^{-1}$ \\
\hline$k_{04}^{\prime}$ & $1.5055 \times 10^{-6}$ & $\mathrm{~m}^{3} \cdot \mathrm{kg}^{-1} \cdot \mathrm{s}^{-1}$ & $E_{a 4}$ & $-2.0227 \times 10^{4}$ & $\mathrm{~J} \cdot \mathrm{mol}^{-1}$ \\
\hline$k_{05}^{\prime}$ & $1.1055 \times 10^{1}$ & $\mathrm{~m}^{3} \cdot \mathrm{kg}^{-1} \cdot \mathrm{s}^{-1}$ & $E_{a 5}$ & $6.7752 \times 10^{4}$ & $\mathrm{~J} \cdot \mathrm{mol}^{-1}$ \\
\hline$k_{06}^{\prime}$ & 8.7398 & $\mathrm{~m}^{3} \cdot \mathrm{kg}^{-1} \cdot \mathrm{s}^{-1}$ & $E_{a 6}$ & $6.7752 \times 10^{4}$ & $\mathrm{~J} \cdot \mathrm{mol}^{-1}$ \\
\hline
\end{tabular}

This analytical model gives PX, OX and MX concentrations knowing the whsv, the temperature and the inlet concentrations. This model uses equilibrium parameters given by Chirico and Steele (1997).

Experimental values versus simulated values (Fig. 11) show that the conversion is slightly better with the model for low whsv (i.e. for high OX conversion). For high whsv, conversion is lower with the model than experimentally. In 


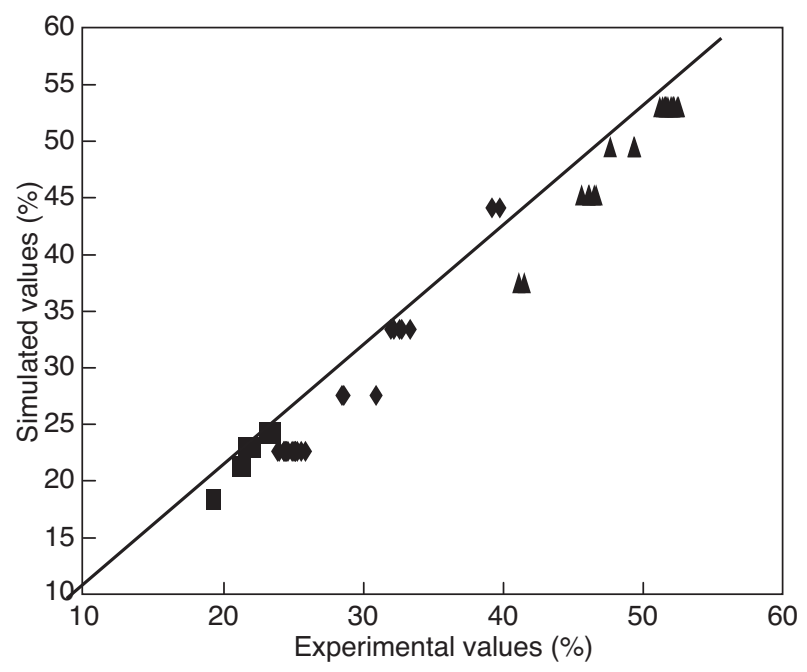

Figure 11

Comparison between experimental and simulated percentage of xylene at $300^{\circ} \mathrm{C}$ with a $50 \%$ TOL-50\% OX feed ( $\mathrm{PX}$, $\Delta \mathrm{MX}, \bullet \mathrm{OX})$.

both cases, simulated \%EA for PX is close to experimental $\%$ EA. This simplified model was implemented in the TMBR model used to study the SMBR process.

\section{MODELING SMBR}

As the SMB system consists of a set of identical columns, a fixed adsorption bed model was implemented.

\subsection{Fixed Adsorption Bed Model}

The main assumptions used to model adsorbent beds are:

- the flow pattern in the bulk phase is modeled by a plug flow model; axial dispersion is taken into account using numerical dispersion of the space discretization scheme (see Sect. 3.4). Danckwerts boundary conditions were used (Ruthven and Ching, 1989);
- pressure drop is neglected;

- the beds are supposed to be under isothermal conditions;

- the adsorbent pellets present a bidispersed porous structure; mass transfer in macroporous and in adsorbed phases are taken into account using a double Linear Driving Force model (Da Silva et al., 1999);

- multicomponent adsorption equilibrium is modeled using the extended multicomponent Langmuir isotherm.

This chromatographic column model was used to simulate the separation/reaction processes.

\subsection{Processes Model}

\subsubsection{SMBR Model}

A SMB unit includes several chromatographic columns. Inlet and outlet ports divide the SMB into four zones. Each column has the outlet of the previous column as an inlet condition except when an external port is present. In this case, a perfect mixing is considered between the outlet of the previous column and the external flow rate (feed, desorbent feed, extract or raffinate). The model of the SMBR process constitutes several identical columns connected by the mass balance at each inlet and outlet port. In the third zone, the fluid phase is converted with the isomerization model described in Section 2.3.

There are different ways of modeling the SMBR. The system can be simulated directly as a cyclic process or using the analogy between the SMBR and True Moving Bed Reactor (TMBR). The SMBR model takes into account the periodic process behavior and gives precise results but requires lengthy computations. To reduce computation time, a TMBR model was developed.

\subsubsection{TMBR Model}

To optimize the process or to estimate operating conditions faster, a model based on the analogy between a SMBR and a True Moving Bed Reactor (TMBR) was implemented. In this model, the solid is moving counter-currently to the liquid flow. Since the switch of the different columns simulates the

TABLE 3

Flow rate and interstitial velocity expression for the use of analog $\mathrm{TMB}(\mathrm{R})$ model

\begin{tabular}{c|c|c|c}
\hline \multirow{2}{*}{ Liquid phase } & & $\mathrm{SMB}(\mathrm{R})$ & $\mathrm{TMB}(\mathrm{R})$ \\
\hline & Interstitial velocity & $v_{S M B(R)}$ & $v_{S M B(R)} \equiv v_{S M B(R)}-u_{S}$ \\
\cline { 2 - 4 } & Volume flow rate & $Q_{S M B(R)} \equiv v_{S M B(R)} A \varepsilon$ & $Q_{T M B(R)} \equiv Q_{S M B(R)}-\frac{\varepsilon}{1-\varepsilon} Q_{S}$ \\
\hline \multirow{2}{*}{ Solid phase } & Interstitial velocity & 0 & $u_{S} \equiv \frac{L_{C}}{\Delta t^{S W}}$ \\
\cline { 2 - 4 } & Volume flow rate & 0 & $Q_{S} \equiv u_{S} A(1-\varepsilon)$ \\
\hline
\end{tabular}


TABLE 4

Geometrics and solids parameters used in simulations

\begin{tabular}{|c|c|c|c|c|c|}
\hline \multicolumn{2}{|c|}{ Reactor parameters } & \multicolumn{2}{|c|}{ Adsorption bed parameters } & \multicolumn{2}{|c|}{ Adsorbent parameters } \\
\hline Length & $8 \mathrm{~m}$ & Length & $1.13 \mathrm{~m}$ & $K_{\text {LDFmicro }}$ & $9.18 \mathrm{~min}^{-1}$ \\
\hline Diameter & $2.4 \mathrm{~m}$ & Diameter & $4.85 \mathrm{~m}$ & $K_{\text {LDFmacro }}$ & $30 \mathrm{~min}^{-1}$ \\
\hline Bed porosity & 0.32 & Bed porosity & 0.321 & Pellet porosity & 0.352 \\
\hline Temperature & $300^{\circ} \mathrm{C}$ & Temperature & $175^{\circ} \mathrm{C}$ & $B_{\mathrm{PX}}$ & $5.865 \mathrm{~m}^{3} / \mathrm{kg}$ \\
\hline \multirow{3}{*}{ Catalyst density } & \multirow{3}{*}{$1150 \mathrm{~kg} / \mathrm{m}^{3}$} & \multirow{3}{*}{ Adsorbent density } & \multirow{3}{*}{$2013 \mathrm{~kg} / \mathrm{m}^{3}$} & $B_{\mathrm{MX}} \& B_{\mathrm{OX}}$ & $1.777 \mathrm{~m}^{3} / \mathrm{kg}$ \\
\hline & & & & $B_{\mathrm{TOL}}$ & $3.827 \mathrm{~m}^{3} / \mathrm{kg}$ \\
\hline & & & & $q_{\text {sat }}$ & $0.15 \mathrm{~kg} / \mathrm{kg}$ \\
\hline
\end{tabular}

intra-granular phase movement in a $\mathrm{SMB}(\mathrm{R})$, and since the switch involves both intra-granular and bulk phases, the analog $\mathrm{TMB}(\mathrm{R})$ process should deal with intra-granular phase velocity (solid velocity) and corrected bulk phase velocities. The flow rate corrections to use with the TMB(R) model are presented in Table 3. In this paper, flow rates presented will be always those of the equivalent $\mathrm{SMB}(\mathrm{R})$.

To model the TMB $(\mathrm{R})$, the fixed bed model described in Section 3.1 is used. The intra-granular movement is added to the macroporous and the adsorbed phase mass balances. In the bulk phase, the only difference with the fixed bed is the correction of flow rate introduced in Table 3.

In the third zone, the variables describing the solid phase directly go to the next part of zone 3 but the variables describing the liquid phase mass fractions are submitted to the isomerization model.

For systems with a great number of adsorption beds, equivalent TMB usually give good results (Schmidt-Traub and Strube, 1996). In our case, with 24 adsorption beds, SMBR and TMBR simulators give very closed results. In the next part of the paper, the SMBR process is studied using the analog TMBR simulator.

\subsection{System Parameters}

The geometric parameters used for SMBR simulations are representative of industrial-scale SMB units. The adsorbent parameters used are representative of a classical molecular sieve used in SMB industrial units. The different parameters are presented in Table 4.

The adsorption column repartition between the different zones is $5-9-7+6-3$. It means that 5 adsorption columns are used in the first zone, 9 in the second zone, etc. (Tab. 5 , Fig. 4). Six reactors have been inserted into the third zone: one before each adsorption column except for the first one. EB has been previously removed with another separation process so there is only a mix of xylene in the feed (Tab. 5).

The flow rates are used to obtain the required performances. Total xylene recovery (TXR), extract PX purity (EPUR, without the desorbent) and productivity (PROD) are
TABLE 5

Feed composition and zone configuration

\begin{tabular}{c|c|c|c}
\hline \multicolumn{2}{c|}{ Feed composition } & \multicolumn{2}{c}{ Zone configuration } \\
\hline Component & Mass fraction & Zone 1 & 5 \\
\hline PX & 0.234 & Zone 2 & 9 \\
\hline MX & 0.396 & Zone 3 & $7+6$ \\
\hline OX & 0.37 & Zone 4 & 3 \\
\hline
\end{tabular}

the criteria used to compare the performances of the studied systems (Eq. 3-5).

$$
\begin{gathered}
T X R=\frac{x_{P X}^{X} Q^{X}}{\left(x_{P X}^{F}+x_{M X}^{F}+x_{O X}^{F}\right) Q^{F}} \\
E P U R=\frac{x_{P X}^{X} Q^{X}}{x_{M X}^{X} Q^{X}+x_{O X}^{X} Q^{X}+x_{E B}^{X} Q^{X}} .
\end{gathered}
$$

$P R O D=\frac{x_{P X}^{X} Q^{X} \rho_{P X}}{V_{b e d} N_{b e d}(1-\varepsilon)} \quad \mathrm{kg}$ of PX $/ \mathrm{m}^{3}$ of adsorbent $/ \mathrm{s}$

\subsection{Numerical Methods}

All the computing codes were developed with the free scientific software Scilab.

A finite volume method is used as the spatial discretization method. A first-order discretization is done and forty volumes per adsorption bed are used. This low number of volumes is used to take into account the axial dispersion of the adsorption columns. As the global dispersion of this system is high, the simulator is not very sensitive to the number of volumes. To reduce the calculation times, a relatively low number was chosen.

The resulting ordinary differential equation system is solved using the DASSL integration routine, already implemented in Scilab. This routine was designed by Petzold and is based on the Petzold-Gear BDF method. 


\section{RESULTS}

In this part, TMB and TMBR simulation results are presented to illustrate the influence of the reaction on the separation process and on the global aromatics loop.

\subsection{Simulation Results}

\subsubsection{Comparison Between the TMB and TMBR}

The first simulations were made with classical SMB parameters. Those SMB parameters were been chosen to achieve industrial performances on EPUR, TXR and PROD.

Industrial specifications on PX fixed the EPUR at more than $99.7 \%$. As we worked on TMB models, the EPUR required was fixed at $99.8 \%$ to be sure that industrial specifications will be achieved with a SMB system.

Usually, the PX recovery is one of the criteria used to evaluate SMB performances on industrial units. PX recovery is the ratio between PX in the extract and PX in the feed. In industrial unit, classical PX recoveries are around 97\%, depending on the feed composition. This recovery corresponds, in our case, to a TXR of $22.7 \%$.

TABLE 6

First parameters used in the TMB model and the TMBR model

\begin{tabular}{c|c}
\hline \multicolumn{2}{c}{ Flow rate parameters } \\
\hline Feed & $220.15 \mathrm{t} / \mathrm{h}$ \\
\hline Desorbent & $264.14 \mathrm{t} / \mathrm{h}$ \\
\hline Extract & $192.02 \mathrm{t} / \mathrm{h}$ \\
\hline Raffinate & $292.28 \mathrm{t} / \mathrm{h}$ \\
\hline 4th zone flow rate & $459.37 \mathrm{t} / \mathrm{h}$ \\
\hline
\end{tabular}

Once the EPUR and the TXR are fixed, zone flow rates are tuned to achieve an acceptable PROD using a classical desorbent consumption (ratio between feed flow rate and desorbent flow rate lower than 1.5). The flow rates obtained with the TMB model are presented in Table 6 .

These flow rates were then tested with the TMBR simulator. The concentration profiles obtained along the adsorber are presented and compared with TMB ones in Figure 12. The performances of the TMBR process are not better than the TMB ones. The PX mass fractions in the extract do not increase and TXR are the same (22.7\%). All PX created in the 3rd zone of the TMBR system goes to the raffinate. Operating conditions appear to be different for reactive or non-reactive systems.

\subsubsection{TMBR Separation Regions}

To determine SMBR operating conditions, separation regions in the 2nd and 3rd zones are studied (Storti et al., 1995).

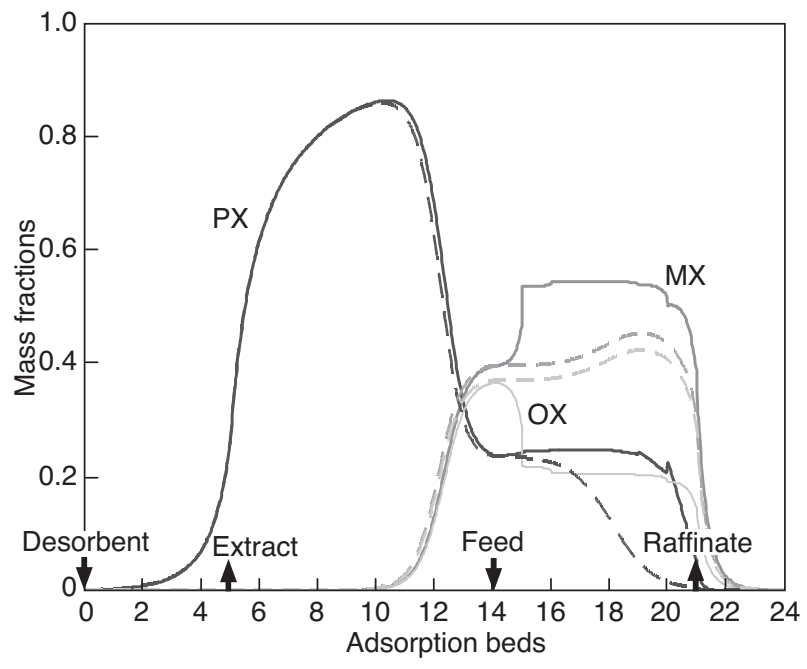

Figure 12

Comparison between TMBR (solid lines) and TMB (dashed lines) concentration profiles along the adsorber for the same operating parameters.

Considering fixed desorbent and 4th zone flow rates, simulations were carried out on a range of extract and feed flow rates in a systematic way, using a grid with constant step to find the separation region where EPUR specification and TXR are obtained.

To obtain those separation regions, the flow rates of the regeneration zones (zones 1 and 4) were chosen to be over their optimal values, i.e. a very low 4 th zone flow rate and a very high zone 1 flow rate, so that only the tuning of the 2 nd and 3rd zones would impact on the process performances.

The TMBR separation regions are compared with those obtained with the TMB system in Figure 13. The regions of pure extract are on the right side of the dashed lines. Regions of required recoveries are under the solid curves (from 22.7 to $80 \%$ of TXR for the TMBR system and for $22.7 \%$ for the TMB system).

For the TMB, TXR cannot exceed $23.4 \%$, which corresponds to a total recovery of the PX injected in the feed. In the non-reactive case, PUR is a function of 2 nd and 3rd zone flow rates. When the 3 rd zone flow rate is reduced, the 2 nd zone flow rate has to be adjusted in order to keep the purity in the specifications.

With the TMBR, TXR can be increased to more than $90 \%$ with a reduction of the 3rd flow rate. As MX and OX are converted into PX in the 3rd zone, the feed flow rate can be reduced without reducing the extract flow rate (and thus the PX productivity). As a result, the reduction of the feed flow rate involves a reduction of the raffinate stream. Less raffinate allows a higher ratio between the fresh feed and 


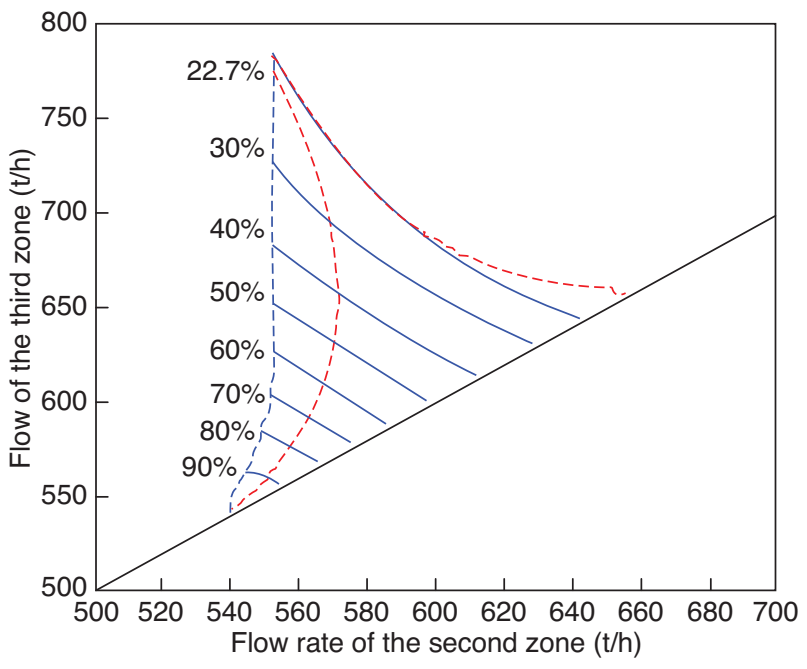

Figure 13

Separation regions for $99.8 \%$ extract purity and various total xylene recoveries for TMBR systems (from 22.7 to $90 \%-$ blue lines) and for TMB (22.7\% - red lines).

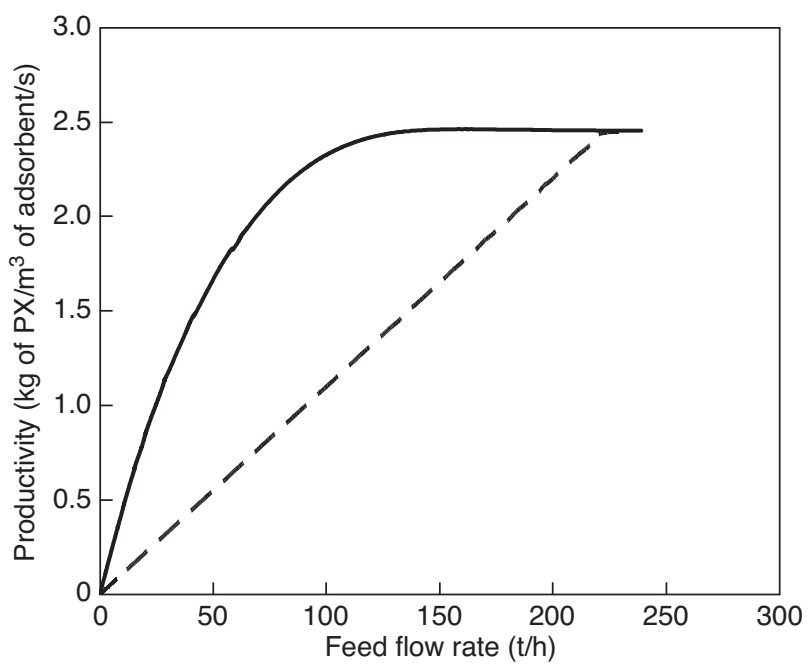

Figure 14

Comparison between TMBR productivity (solid line) and TMB productivity (dashed line) function of feed flow rates for the maximum extract flow rate.

recycle feed. As the global feed process must be constant, the feed flow rate of TMBR has to be adjusted to have the same productivity.

\subsubsection{Optimization of the Feed Flow Rate}

The maximum feed flow rate admitted by the TMB process in this case is $229 \mathrm{t} / \mathrm{h}$. The TMB maximum capacity is $2.448 \mathrm{~kg} / \mathrm{m}^{3} / \mathrm{s}$ (maximum of the dashed line in Fig. 14).

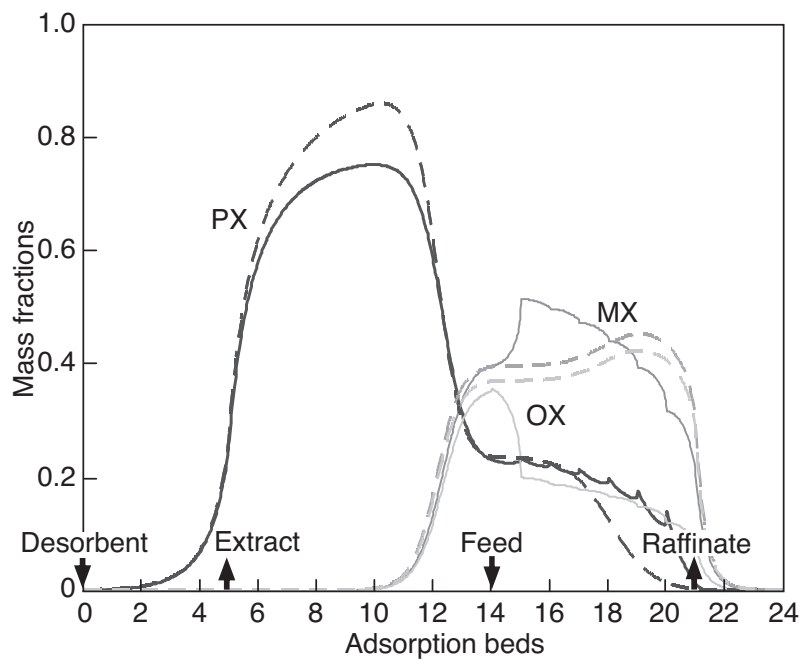

Figure 15

Comparison of the concentration profiles along the adsorbers for a TMBR (solid lines) and a TMB (dashed lines) with equivalent productivity.

Our objective is to keep the productivity constant, but with a reduction of the raffinate flow rate thanks to the reactive separation.

To compare TMB and TMBR results, we simulated TMB and TMBR systems for various feed flow rates located on the purity curve (dashed line in Fig. 13). The influence of the feed flow rate on PROD for the TMB and the TMBR systems is compared in Figure 14.

Maximum feed flow rates are almost identical for the two systems but the feed flow rate of the TMBR process can be reduced without losing PROD. For the TMB, when the feed flow rate is reduced, PROD is also reduced. The TMBR feed flow rate can be reduced to $133.7 \mathrm{t} / \mathrm{h}$ without losing productivity. Below this flow rate, the TMBR productivity starts to decrease. Over this flow rate, the TMBR productivity increases slightly, but the raffinate flow rate (i.e. the recycle stream) increases, so this tuning is not interesting.

The TMBR process can reach the TMB maximum PROD with a decrease of $42.6 \%$ in the feed flow rate $(128.5 \mathrm{t} / \mathrm{h}$ instead of $220.2 \mathrm{t} / \mathrm{h}$ ). The concentration profiles along the adsorber obtained considering TMB and TMBR processes are shown in Figure 15, for the maximum TMB productivity.

The PX mass fraction in the extract is the same for the TMB and TMBR (Fig. 15), whereas the feed flow rate of the TMBR is $40 \%$ lower than the TMB one (Fig. 14). The major part of the PX created in the 3rd zone has been recovered in the extract. The TXR has increased from $22.7 \%$ to $38.9 \%$. The same productivity is obtained with a $31.5 \%$ reduction of the raffinate flow rate. This reduction involves important changes in the recycle loop. This example of reduction is treated in the last part of this paper. 


\subsection{Example of the Reduction of Recycle Loop}

The main flow rates of the global schemes displayed in Figure 16 are presented in Table 7 . The reactive case is compared with the classical PX production process with TOL as a desorbent to simplify the global scheme comparisons. The fresh feed for the two systems is $50 \mathrm{t} / \mathrm{h}$.

As the fresh feeds are the same, the PX productivities are also the same because the losses in the distillation columns and in the isomerization reactor are neglected.

A reduction of $41.6 \%$ of the feed flow rate was obtained using a TMBR. This reduction leads to a reduction of $31.5 \%$ of the raffinate flow rate and $53.9 \%$ of the isomerization reactor feed. It also allows a reduction of $58.4 \%$ of the xylene distillation column feed.

TABLE 7

Example of the reduction of the recycle feed, raffinate stream and multi-column process feed for a PX production of $50 \mathrm{t} / \mathrm{h}$

\begin{tabular}{c|c|c|c}
\hline & With SMB & \multicolumn{2}{|c}{ With SMBR } \\
\hline & \multicolumn{1}{|c|}{$\mathrm{t} / \mathrm{h}$} & $\mathrm{t} / \mathrm{h}$ & $\%$ of the classical case \\
\hline Fresh feed & 50.0 & 50.0 & 100.0 \\
\hline Adsorber feed & 220.2 & 128.5 & 58.4 \\
\hline Raffinate stream & 292.3 & 200.3 & 68.5 \\
\hline Isomerization reactor flow rate & 170.2 & 78.5 & 46.1 \\
\hline Xylene distillation feed & 220.2 & 128.5 & 58.4 \\
\hline
\end{tabular}

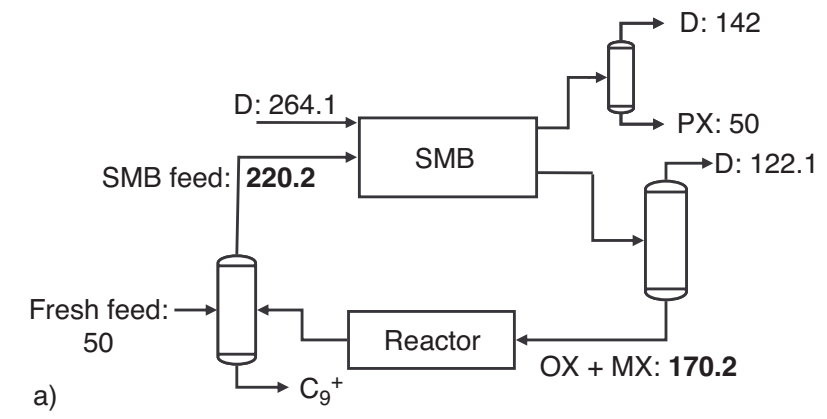

a)

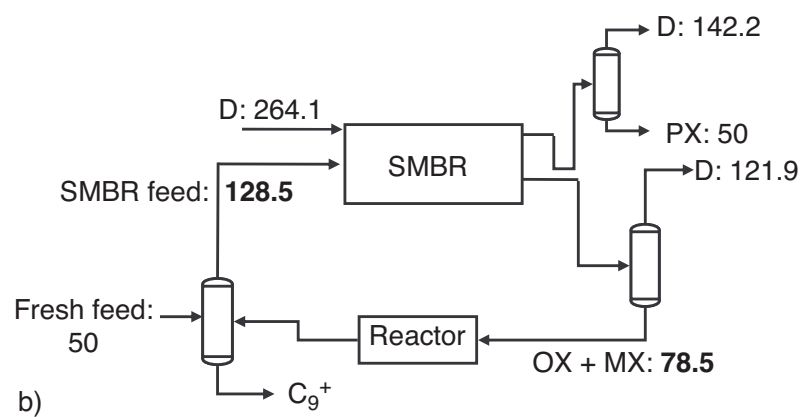

Figure 16

Main flow rates of the two schemes for a production of $50 \mathrm{t} / \mathrm{h}$ of pure PX. a) with SMB, b) with SMBR.
A multi-column system will involve a greater investment for reactive cases. The most important factors of the investment increase are adding the reactors and elevating the functioning pressure. As the temperature is higher for a reactive multi-column system, the pressure is increased to stay in the liquid phase. Additional valves and a slight design modification are also required to integrate reaction in the adsorber.

However, a reduction of investment costs is expected in the $\mathrm{C}_{8}$ aromatic distillation column, in the raffinate distillation columns and in the external isomerization reactor. The recycle loop also involves a reduction in energetic use for the three distillation columns, for the pumps used in the recycling loop and for the isomerization reactor.

A precise economic evaluation should be made to quantify the gains expected with the scheme using the reactive separator. This scheme also has to be compared with an actual PX production plant using PDEB as a desorbent. In fact, the energetic reduction in the extract and raffinate distillation columns with the PDEB has to be compared with the savings expected with the scheme using the SMBR.

\section{CONCLUSION AND PERSPECTIVES}

This work focuses on the use of a SMBR for PX production. A reaction step is added to the SMB separation process by inserting reactors between the adsorption columns of the $3 \mathrm{rd}$ zone. This reaction integration should permit one to reduce the recycle loop (external isomerization reactor size and the distillation column sizes).

As separation occurs in the liquid phase, conversion of $\mathrm{MX}$ and $\mathrm{OX}$ into PX was investigated in the liquid phase. Satisfactory conversion levels were obtained with pure OX feed for several whsv and for a temperature range from $250^{\circ} \mathrm{C}$ to $300^{\circ} \mathrm{C}$. The classical desorbent, PDEB, was discarded because of its conversion into ODEB and MDEB on the chosen catalyst. Toluene is preferred as desorbent. Tests with diluted feed $(50 \%$ OX/50\% TOL) show that TOL has no effect on conversion. These tests validated the feasibility of liquid phase isomerization of xylene on a HZSM-5 catalyst under SMBR conditions (high whsv and large amount of TOL as a desorbent).

An analytical isomerization model was added to a TMB model to obtain a TMBR simulator used to study the SMBR process. The simulation results underline the differences in the operating conditions of a SMBR. To increase the PX recovery, feed has to be decreased. This reduction of the feed allows the expected reduction of the recycling flow rate. In view of the two global schemes of PX production, economic savings might be expected on investment and operating costs.

The number and the size of the isomerization reactors have not yet been optimized. A slight gain in desorbent consumption can also be expected. This optimization will be 
included in a future study. This new study has to compare this new process (including the optimized SMBR) and the current industrial process which uses PDEB as a desorbent. This new study will include the influence of TOL use on the two desorbent distillation columns (extract and raffinate distillation). Finally, those results have to be validated by experimental results. A SMBR will be carried out on a new and original pilot unit: "one-column reactor". Based on the "one-column analog", first studied by Abunasser et al. (2003), it should allow the SMBR study with only one adsorption column and one isomerization reactor. This global study, including experimental tests, economic evaluation and modeling results, will quantify the potential of the SMBR for PX production.

\section{ACKNOWLEDGMENT}

This work was financed by the FUI within the framework of Axelera project (Intensification de Procédés).

\section{REFERENCES}

Bergeot G., Leinekugel-Le-Cocq D., Leflaive P., Laroche C., Muhr L., Bailly M. (2009) Simulated moving bed reactor for paraxylene production, Chem. Eng. Trans. 17, 87-92.

Chirico R.D., Steele W.V. (1997) Thermodynamic Equilibria in Xylene Isomerization. 5. Xylene Isomerization Equilibria from Thermodynamic Studies and Reconciliation of Calculated and Experimental Product Distributions, J. Chem. Eng. Data 42, 4, 784-790.

Da Silva F.A., Silva J.A., Rodrigues A.E. (1999) A General Package for the Simulation of Cyclic Adsorption Processes, Adsorption 5, 3, 229-244.

Dulot H. (2000) Modélisation de réacteurs-adsorbeurs mis en œuvre en lit simulé. Application à la conversion et à la séparation d'hydrocarbures aromatiques, $P h D$ Thesis, novembre 2000.
Fish B., Carr R.W., Aris R. (1986) The continuous countercurrent moving bed chromatographic reactor, Chem. Eng. Sci. 41, 4, 661-668.

Ganetsos G., Barker P.E., Ajongwen J.N. (1993) Batch and continuous chromatographic systems as combined bioreactorseparators, in Preparative and production scale chromatography, Ganetsos G., Barker P.E. (eds), Marcel Dekker.

Hashimoto K., Adachi S., Noujima H., Ueda Y. (1983) A new process combining adsorption and enzyme reaction for producing higher-fructose syrup, Biotechnol. Bioeng. 25, 10, 2371-2393.

Kurup A.S., Subramani H.J., Hidajat K., Ray A.K. (2005) Optimal design and operation of SMB bioreactor for sucrose inversion, Chem. Eng. J. 108, 1-2, 19-33.

Lode F., Houmard M., Migliorini C., Mazzotti M., Morbidelli M. (2001) Continuous reactive chromatography, Chem. Eng. Sci. 56, 2 , 269-291.

Minceva M., Gomes P.S., Meshko V., Rodrigues A.E. (2008) Simulated moving bed reactor for isomerization and separation of p-xylene, Chem. Eng. J. 140, 1-3, 305-323.

Ruthven D.M., Ching C.B. (1989) Counter-Current and Simulated Counter-Current Adsorption Separation Processes, Chem. Eng. Sci. 44, 1011-1038.

Sardin M., Schweich D., Villermaux J. (1993) Preparative fixed-bed chromatographic reactor, in Preparative and production scale chromatography, Ganetsos G., Barker P.E. (eds), Marcel Dekker.

Schmidt-Traub H., Strube J. (1996) Dynamic simulation of simulated-moving-bed chromatographic processes, Comput. Chem. Eng. 20, Supplement 1, S641-S646.

Storti G., Baciocchi R., Mazzotti M., Morbidelli M. (1995) Design of Optimal Operating Conditions of Simulated Moving Bed Adsorptive Separation Units, Ind. Eng. Chem. Res. 34, 1, 288-301.

Takeuchi K., Uraguchi Y. (1977) Experimental studies of a chromatographic moving-bed reactor, J. Chem. Eng. Jpn 10, 6, 455-460.

Takeuchi K., Uraguchi Y. (1976) Separation conditions of the reactant and the product with a chromatographic moving bed reactor, J. Chem. Eng. Jpn 9, 2, 164-166.

Yu W., Hidajat K., Ray A.K. (2005) Optimization of reactive simulated moving bed and Varicol systems for hydrolysis of methyl acetate, Chem. Eng. J. 112, 1-3, 57-72.

Final manuscript received in November 2009 Published online in October 2010 